\title{
Tracking the Evolution of Abnormal Grain Growth in Grain-Oriented Electrical Steels by Coercivity Measurements
}

\author{
V. Stoyka ${ }^{a, *}$, F. KovaC ${ }^{a}$, I. Petryshynets ${ }^{a}$ And I. SchindleR ${ }^{b}$ \\ ${ }^{a}$ Institute of Materials Research, Department of Microstructural Engineering of Steels, Slovak Academy of Sciences \\ Watsonova 47, 04001 Košice, Slovak Republic \\ ${ }^{b}$ Faculty of Metallurgy and Materials Engineering, VSB-Technical University of Ostrava, Ostrava, Czech Republic
}

The measurements of coercivity were utilised to investigate the main evolution stages of abnormal grain growth in grain-oriented electrical steels. The investigated grain-oriented steels were taken from industrial line after final cold rolling. The steels were subjected to short time annealing at elevated temperatures with high heating rates. The coercivity measurements carried out within the present work were confronted with microstructure and texture analysis in order to show the direct dependence of the measured coercivities on metallurgical characteristics of the investigated steel. It is shown that the coercivity measurements technique could capture main microstructural changes taking place in recrystallization.

PACS numbers: 74.25.Ha, 75.20.En, 75.50.Bb, 75.50.Gg

\section{Introduction}

Grain-oriented (GO) steels are soft magnetic materials widely used for power, distribution transformer and large generators cores. Magnetization of the GO steels primarily accompanied by motion of domain walls and the eddy current caused by the domain wall motion brings about losses. The ideal model assumes that for [001]-directed materials all domain walls consist of $180^{\circ}$ walls (a transition of magnetic moment between neighboring domains with an angular displacement of $180^{\circ}$ ) and they move homogeneously at the same speed [1]. An observation of dynamic domain wall movement has revealed that this motion is not uniform and is affected by magnetic defect structures [2]. The GO steels are characterized by the sharp $\{110\}\langle 001\rangle$ crystallographic texture or so-called Goss texture [3]. When the [001] easy axis of magnetization is inclined about $0.5^{\circ}$ or more with respect to the rolling plane, the auxiliary domains are formed that have magnetization components in the [100] or [010] direction. The number of these surface closure domains increases with increase of an angle of inclination of the [001] axis, and becomes zero when the angle of inclination of these axis is $0.5^{\circ}$ or less [2]. The improvement of the GO steel quality can be achieved mainly by improvements of the $\{110\}\langle 001\rangle$ texture.

Due to aforementioned facts the investigation of recovery, recrystallization, grain growth and texture develop-

* corresponding author; e-mail: vstoyka@imr.saske.sk ment processes are predominant from the improvement of the GO steel point of view. The progress in sub- and structural changes can by determined by monitoring any physical property which is dependent on density of dislocation, grain boundaries and texture state as well. Such properties include electrical resistivity $[4,5]$, hardness $[6,7]$, tensile test $[8,7]$, and other mechanical properties [7]. The advantages of such methods lie in a relative simplicity and in a reasonable response to the changes in microstructures of the materials. However, due to difficulty in distinguishing of between different structure evolution phenomena, none of the method could be applied as a comprehensive one; all of them should be amplified with each other. Moreover, many of these methods are destructive and characterized by difficulty in distinguishing of different restoration processes.

The precise estimation of the relationship between microstructure, texture, precipitations state and domain wall motion in the material could be obtained from the measurement of the coercivity. The investigation of the main stages of microstructure and texture development in the GO steel with the coercivity measurements is presented within the paper. The performed measurements were confronted with metallographic and electron backscattered diffraction (EBSD) analyses.

\section{Material and methods}

The material investigated in this work was a GO steel with the following chemical composition: $\mathrm{C}=0.005$, $\mathrm{Mn}=0.19, \mathrm{Si}=3.1, \mathrm{P}=0.007, \mathrm{~S}=0.008, \mathrm{Cr}=0.04$, 
$\mathrm{Ni}=0.03, \mathrm{Cu}=0.45, \mathrm{Al}=0.011, \mathrm{~N}=0.01 \mathrm{wt} \%$. A sheet of $0.33 \mathrm{~mm}$ thickness was taken after a final cold rolling from an industrial line.

The samples of dimension $3 \mathrm{~cm} \times 1 \mathrm{~cm}$ with the longest side parallel to the rolling direction were heated to different temperatures in the range $850-1150{ }^{\circ} \mathrm{C}$ with heating rates higher than $10^{\circ} \mathrm{C} / \mathrm{s}$ and were kept at the particular temperature for $5 \mathrm{~min}$ in a dry hydrogen atmosphere.

After the annealing, coercivity measurements were performed on each sample. These measurements were carried out with an Oersted type coercivity meter KPC-1. The specimen was saturated in the homogeneous part of the field of the coercivity meter's solenoid. Subsequently the magnetic field strength was slowly increased in the reverse direction, until the polarization of the specimen passes zero. This reverse field at zero flux density was taken as the coercivity.

The most representative samples were chosen for microstructure and texture analysis. The texture analysis was carried out by an EBSD method in the normal direction plane for each sample of $1.5 \mathrm{~cm} \times 1 \mathrm{~cm}$ in size.

\section{Results and discussion}

Inverse pole figure (IPF) maps representing both the microstructure and orientation of particular grains were constructed on the base of EBSD data. Figure 1 presents the IPF maps obtained from the investigated GO steel annealed at different temperatures. The orientation distribution functions (ODF) were built from the acquired EBSD data. In case where the sample dimension of $1.5 \times 1 \mathrm{~cm}^{2}$ did not allowed for an acquire of the EBSD data from at least 300 grains another sample with the same dimensions was prepared from the same specimen. The data obtained from samples prepared from one specimen were stitched together and then the ODF were calculated, this was in case of samples where complete abnormal grain growth was observed, see Fig. 1c.

The ODF's sections taken at $\varphi_{2}=45^{\circ}$ are shown in Fig. 2. The presented ODF section shows main texture states of the microstructures presented in Fig. 1. Figure 1a represents fully recrystallized microstructure obtained after annealing at $1030{ }^{\circ} \mathrm{C} / 5 \mathrm{~min}$. This state is characterized by quite strong $\gamma$-fiber's texture components (this fiber represents groups of all orientations for which $\langle 111\rangle \| \mathrm{ND}, \mathrm{ND}$ - normal direction), see Fig. 2a. The increase of temperature up to $1040^{\circ} \mathrm{C}$ initiates commencement of an abnormal grain growth of grains with (110)[001] orientation, see Fig. 1b. Here the strengthening of the Goss texture component and subsiding of $\gamma$-fiber's texture components is clearly seen in Fig. 2b. This results in bimodal microstructure development where an abnormally growing grain consumes a matrix of the primary recrystallized grains.

The annealing of the GO steel at $1050{ }^{\circ} \mathrm{C}$ results in a sharp Goss texture development by abnormal grain growth, see Fig. 1c and 2c. The increase of the annealing temperature to $1200{ }^{\circ} \mathrm{C}$ led to strengthening of $\gamma$-fiber's and weakening of the Goss texture component as it is shown in Fig. 2d. It means that annealing of the GO steel at very high temperatures violates the selectivity conditions for the Goss grains development. Here, grains with different orientations have been developed almost equally, see Fig. 1d.

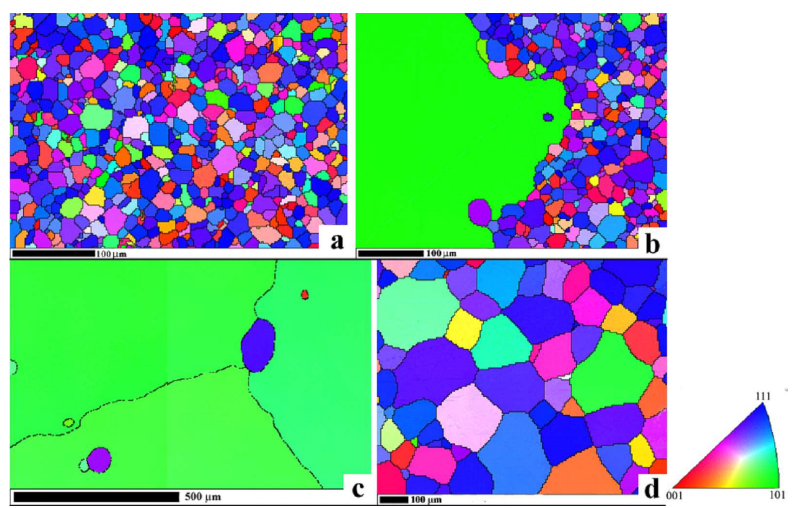

Fig. 1. IPF maps showing developed microstructure in the GO steel after annealing at (a) $1020{ }^{\circ} \mathrm{C}$, (b) $1040{ }^{\circ} \mathrm{C}$, (c) $1075^{\circ} \mathrm{C}$ and (d) $1150^{\circ} \mathrm{C}$ for 5 min.

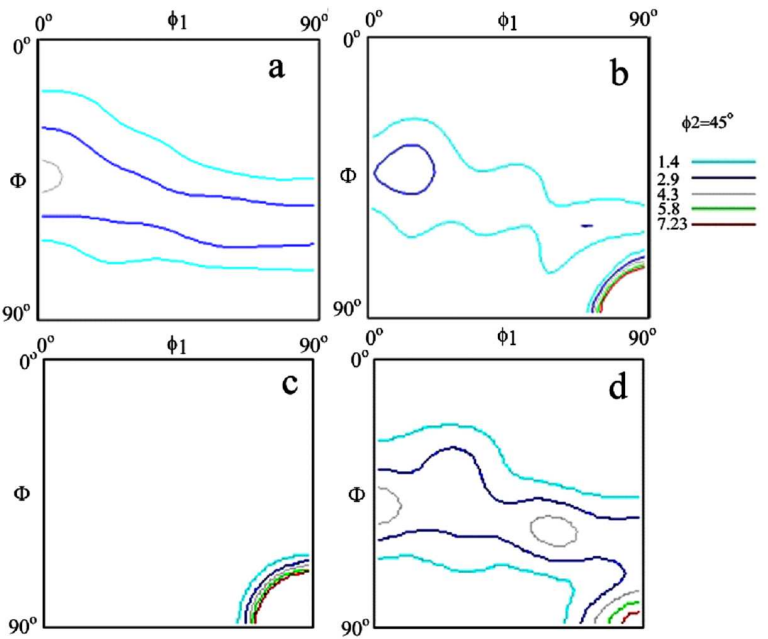

Fig. 2. ODF sections at $\phi 1=45^{\circ}$ obtained from the investigated GO steels treated under dynamical heat treatment conditions for $5 \mathrm{~min}$ at (a) $8500^{\circ} \mathrm{C}$, (b) $1040^{\circ} \mathrm{C}$, (c) $1075^{\circ} \mathrm{C}$ and (d) $1150{ }^{\circ} \mathrm{C}$.

The measurements of coercivities were used to follow the main changes in the microstructure and texture of the samples. Figure 3 represents a set of measurements on the sample annealed at temperature range $1020-1200{ }^{\circ} \mathrm{C}$. The GO steel in primarily recrystallized state has $H_{\mathrm{C}}$ values around $100 \mathrm{~A} / \mathrm{m}$. The nucleation of abnormal grain growth leads to drastic decrease of the $H_{\mathrm{C}}$ value to around $47 \mathrm{~A} / \mathrm{m}$. The further decrease and then plateau behavior of the $H_{\mathrm{C}}$ values corresponds to abnormal grain growth development. The GO steel with coarse-grained microstructure had the $H_{\mathrm{C}}$ values around $10-14 \mathrm{~A} / \mathrm{m}$. 


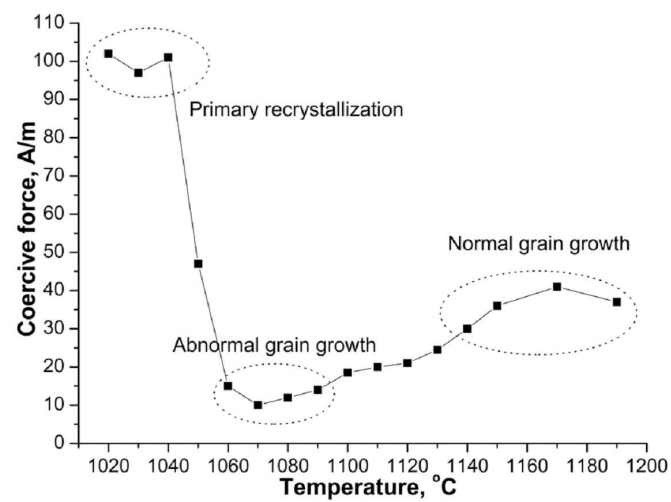

Fig. 3. Dependence of coercivity values on the annealing temperature applied to the investigated GO steels.

The slight increase of coercivity values with further rise of the temperature can be assigned to start of development of grains with orientation different from the Goss one. This phenomenon strengthens as the temperature increases and the $H_{\mathrm{C}}$ achieves its threshold value around $40 \mathrm{~A} / \mathrm{m}$, see Fig. 3. These measured values correspond to microstructure presented in Fig. 1d, where grains possessing different orientation develop almost equally.

The aforementioned results clearly showed that the microstructure and texture evolution in the investigated material can be captured by coercivity measurements. The main stages in microstructure and texture development of the investigated GO steel are marginally denoted in Fig. 3. Hence, the coercivity measurements are sensitive not only to microstructure changes but also to the Goss texture development. This is particularly seen from the plateau behavior of $H_{\mathrm{C}}$ curve, see Fig. 3. The coercivity of the investigated steel passed through secondary recrystallization with moderate texture is much higher than that of the textured material, see coercivity values of the materials annealed after $1140{ }^{\circ} \mathrm{C}$ in Fig. 3. Moreover, an additional example of coercivity change in materials with moderate texture was shown in paper by Sidor et al. [9]. Here the recovery, recrystallization and grain growth processes were distinguished and the $H_{\mathrm{C}}$ curve behavior had the similar character as that observed in the present paper.

\section{Conclusions}

The microstructure and texture evolution versus applied heat treatment conditions in the GO steel were investigated. It was shown that there were three main stages in microstructure and texture development of the GO steel. The first is primary recrystallization that was characterised by domination of $\gamma$-fiber's texture components, the second stage is abnormal grain growth with development of strong $\{110\}\langle 001\rangle$ texture. The third stage is a normal grain growth that proceeds through almost equal growth of grains with different orientation, such a microstructure revealed coexistence of both $\gamma$-fiber's and (110)[001] texture components. All the mentioned microstructure and texture stage were detected and clearly distinguished by the coercivities measurements. Moreover, the threshold temperatures of the above described processes could be distinguished by this method.

Concluding the results of the present work one can summarise that the coercivities measurements give a good reflection of microstructure and texture development in the GO steels.

\section{Acknowledgments}

This work was carried out within the frame of the project "Technology of preparation of electrotechnical steels possessing high permeability aimed for high affectivity electromotors", ITMS 26220220037 financed through European Regional Development Fund. The work is also supported by Slovak Grant Agency under the contract number VEGA-2/0138/10.

\section{References}

[1] R.H. Pry, C. Bean, J. Appl. Phys. 29, 532 (1958).

[2] T. Nozawa, M. Mizokami, H. Mogi, Y. Matsuo, IEEE Trans. Magn. MAG-32, 572 (1996).

[3] M. Matsuo, ISIJ International 29, 809 (1989).

[4] T. Narutani, J. Takamura, Acta Metal. Mater. 39, 2037 (1991).

[5] T. Taoka, K. Suzuki, A. Yoshikawa, M. Okamoto, Acta Metal. 13, 1311 (1965).

[6] C.M. Kamma, E. Hornbogen, Mater. Res. Bull. 18, 1027 (1983).

[7] F.J. Humphreys, M. Hatherly, Recrystallization and Related Annealing Phenomena, Elsevier, Oxford 1996, p. 317.

[8] F. Tehovnik, B. Arzensek, B. Arh, Metalurgija 47, 75 (2008).

[9] Y. Sidor, F. Kovac, T. Kvackaj, Acta Mater. 55, 1711 (2007). 